\title{
Medicina y accidentes de tránsito.
}

El médico Ricardo L. Flores, oftalmólogo de amplísima visión, famoso por otras innovaciones médicas, según asevera Basadre (1), trajo a Lima el primer automóvil que, en 1903, exactamente hace cien años, circuló por sus calles, tres años antes que el primer tranvía eléctrico. En 1907 había unos 25 automóviles. En esa época, nadie se hubiera atrevido a pensar que al finalizar el siglo XX, Perú registraría más de un millón de vehiculos automotores.

El automóvil transformó la vida de la ciudad y del campo, pero junto con sus innumerables beneficios introdujo una pesada carga de lesión, discapacidad y muerte; perjuicios que el desarrollo social y la innovación tecnológica han logrado disminuir.

Con relativa prontitud, antes de la Primera Guerra Mundial, quedaron proscritos los parabrisas de vidrio corriente que ocasionaban severas lesiones en rostro, en tanto que el arrancador accionado por batería remplazaba, progresivamente, la manivela de arranque manual que podía lesionar al operador. Sólo después de la Segunda Guerra Mundial se comenzó a dar atención a la peligrosidad del timón y del tablero, ambos trasmitían toda la energía del impacto sin deformarse ni disminuirla. En el mundo, el cinturón de seguridad pasó a ser equipo estándar en la década de los sesentas y, posteriormente, se añadió el "air bag".

La vialidad, las normas que regulan el tránsito y las prácticas sociales observadas en el flujo de vehículos y peatones, se convirtieron en indicadores de civilización moderna. El lenguaje icónico de señales de tránsito plasmó un conjunto de símbolos universales, consolidados mucho antes que Mc Luhan (1968) acuñara el término Globalización.

Durante el siglo XX la velocidad se convirtió en un peligro socialmente aceptado y subestimado. En efecto, con los conocimientos de secundaria, cualquiera acepta que "30 kilómetros por hora" ("30 mil metros por hora") es la velocidad a la que toca suelo quien se precipita desde 9 metros de altura, vale decir, del techo de un tercer piso. Sin embargo, conducimos sin temor a velocidades de $90 \mathrm{~km} / \mathrm{hora}$.

En el Perú, los accidentes de tránsito ocasionan cada década alrededor de treinta mil muertes. En el mundo, cada año, 1.25 millones. En respuesta a problema de tal magnitud, el Lema de la OMS para el día de la Salud en el año 2004, es “Safe Roads"(2).

El estudio de lesión por Trauma, en cuanto a la naturaleza de la lesión, corresponde fundamentalmente a la medicina. No podemos sostener lo mismo respecto de la génesis del trauma. La etiología bio-física y sobre todo la etiología bio-social, es decir las "causas externas", convocan numerosas disciplinas, profesiones, e instituciones. Una fuente particular de dificultades para tales estudios, surge de las responsabilidades civiles y legales de los actores involucrados, emparejadas a competencias asignadas por el Estado a las diferentes instituciones encargadas de dilucidar tales responsabilidades.

A través del Hospital Nacional Cayetano Heredia, la Universidad ha contribuido a desarrollar las bases para la investigación no sólo de patologías que resultan de tales accidentes sino de la incorporación de una visión integral de los accidentes y violencias que incluya la exploración de su causalidad bio-social. 
La UPCH (3) y el HNCH han dado la organización, cultura e infraestructura para desarrollar investigaciones sobre accidentes y violencias. La preparación del campo para abordar el tema incluye consolidación de estándares de diagnóstico del caso individual y plataformas de registro sistemático de la casuística y de sus causas. Contando con estos prerrequisitos, puede recién llevarse a cabo estudios del tipo serie de casos o de tipo descriptivo.

En el Hospital Nacional Cayetano Heredia, en la década de los setentas la meta era lograr que los cambiantes equipos médicos asistenciales de alta rotatividad registraran los diagnósticos de todos los pacientes. Luego de alcanzar esta meta, expandimos la rutina del diagnóstico limitado al tipo nosológico de lesión a la rutina que precisa, además del tipo de lesión y de su localización, el registro de causa externa (3). Para ello fue preciso instaurar una clasificación jerarquizada de causas externas compatible con la racionalidad del trabajo médico en Emergencia, sometida a la presión dramática de la urgencia, racionalidad emocionalmente adversa al registro de datos en tiempo real. La realidad que viven los servicios de emergencia, hace materialmente imposible la aplicación -tanto directa inmediata como la que posteriormente pudieran efectuar los codificadores de datos crudos o relatos- de lo establecido como causas externas en la CIE 9 y CIE 10 por la OMS.

Sin embargo, antes que las computadoras personales XT y AT pudieran manejar bases de datos no numéricas (strings), la Emergencia del Hospital Cayetano Heredia manejaba un código de siglas que incluía lesiones y causas externas (4). La ventaja comparativa de nuestra Universidad en el uso de esta tecnología permitió consolidar aprovechar y mantener los avances logrados.

Gracias a la cultura institucional, tanto del HNCH como de la UPCH, el servicio de emergencia del HNCH mantiene vigente desde hace 19 años el Registro Sistemático de Causas Externas, que proporciona un marco confiable para todas las investigaciones sobre accidentes y violencias desarrolladas a partir de los datos de 1984. Este recurso, ahora que el enfoque de causas externas destaca varios problemas prioritarios de salud pública, da al HNCH una ventaja comparativa para avanzar con estudios analíticos y proyectos de intervención.

La oportunidad está dada para los estudios de evaluación económica del tratamiento efectivo (5) así como para introducir protocolos de atención, escalas anatómicas y funcionales de trauma, y diseño evaluación y monitoreo de medidas de prevención.

En este número de la Revista Médica Herediana el trabajo del Dr. Rey de Castro abre la exploración del problema de somnolencia como factor causal de los accidentes de tránsito en carreteras, situación de consecuencias mortales o muy graves que con frecuencia dañan a terceros.

\section{REFERENCIAS BIBLIOGRAFICAS}

1. BASADRE JORGE: Historia de la República del Perú. Tomo XVI, pp 90, Edit Universitaria Lima Perú 1968

2. http://www.who.int/dg/speeches/2003/london/en/.

3. González D: Clasificación Jerarquizada de Causas Externas. (Tesis Grado de Doctor en Medicina) UPCH 1992.

4. González D, Chaparro J, De las Casas E: Siglas de Uso Hospitalario. Notación Abreviada de Uso Interno del
Hospital Cayetano Heredia. Serie MAP. Prensas Universitarias UPCH, LIMA. 1968

5. Bambaren C: Aspectos económicos en salud de los accidentes de tránsito en la ciudad de Lima. (Tesis Grado Doctor en Medicina) UNSM, Lima. 2003

Diego González del Carpio *

* Profesor Principal UPCH, MPH Doctor en Medicina, Jefe Departamento Emergencia HNCH 1973-1990, Presidente (1986-1990) de la Comisión Permanente del Sistema de Emergencia de Lima Callao. 